\title{
Performance of a Cross-Flow Humidifier with a High Flux Water Vapor Transport
}

\section{Membrane}

R. K. Ahluwalia ${ }^{1 *}$, X. Wang ${ }^{1}$, W. B. Johnson ${ }^{2}$, F. Berg ${ }^{3}$ and D. Kadylak ${ }^{4}$

${ }^{1}$ Argonne National Laboratory, 9700 S Cass Avenue, Argonne, IL 60439, USA

${ }^{2}$ W. L. Gore \& Associates, Inc. (Retired), Newark, DE, USA

${ }^{3}$ Ford Motor Corporation, Dearborn, MI, USA

${ }^{4}$ dPoint Technologies, Inc., Vancouver, BC, Canada

\section{Abstract}

Water vapor transport (WVT) flux across a composite membrane that consists of a very thin perfluorosulfonic acid (PFSA) ionomer layer sandwiched between two expanded polytetrafluoroethylene (PTFE) microporous layers is investigated. Static and dynamic tests are conducted to measure WVT flux for different composite structures; a transport model shows that the underlying individual resistances for water diffusion in the gas phase and microporous and ionomer layers and for interfacial kinetics of water uptake at the ionomer surface are equally important under different conditions. A finite-difference model is formulated to determine water transport in a full-scale (2- $\mathrm{m}^{2}$ active membrane area) planar cross-flow humidifier module assembled using pleats of the optimized composite membrane. In agreement with the experimental data, the modeled WVT flux in the module increases at higher inlet relative humidity (RH) of the wet stream and at lower pressures, but the mass transfer effectiveness is higher at higher pressures. The model indicates that the WVT flux is highest under conditions that maintain the wet stream at close to $100 \% \mathrm{RH}$ while preventing the dry stream from becoming saturated. The overall water transport is determined by the gradient in $\mathrm{RH}$ of the wet and dry streams but is also affected by vapor diffusion in the gas layer and the microporous layer. Keywords: Polymer electrolyte fuel cells; membrane humidifier; composite membrane; water vapor transport; combined thermal and mass transfer.

*Corresponding author: walia@anl.gov; T: 1-630-252-5979; F: 1-630-252-3296 


\section{Introduction}

Most of the polymer electrolyte fuel cell stacks for automotive applications currently require that the inlet cathode air be humidified for extended durability and acceptable performance $[1-4]$. External humidification becomes even more essential as the automotive manufacturers attempt to increase the stack temperature to above $90^{\circ} \mathrm{C}$ in order to satisfy heat rejection requirements [5]. Extensive research effort is being dedicated to develop high-temperature polymer membranes that have acceptable proton conductivity under dry conditions, but formidable technical and material issues remain to be overcome [6,7]. Some manufacturers have successfully practiced internal humidification for water management but the stack temperatures are generally lower than $90^{\circ} \mathrm{C}[8,9]$.

Both active and passive methods have been employed for external humidification of the cathode air [10 - 12]. Active methods involving direct injection of liquid water with spray nozzles are not considered attractive since they require either carrying consumable water on-board the vehicle (unacceptable) or using a condenser to recover water formed in the fuel cell which adds to the system complexity $[1,2]$.

Enthalpy wheel humidifier is an example of the passive humidification method [11]. It consists of a thin-walled, desiccant-coated (400 or more cells per square inch) monolith that is rotated at 10-60 rpm (revolutions per minute) to contact the dry inlet air and wet depleted cathode exhaust at different times during a single revolution. The desiccant absorbs moisture as it contacts the wet stream and releases moisture as it contacts the dry stream. Perfluorosulfonic acid (PFSA) based membrane humidifiers have also been built [12]. In one such device tested, the humidifier required 7,000 hollow Nafion fibers of 1-mm internal and 1.2-mm external diameter $(100 \mu \mathrm{m}$ fiber thickness) for an 80-kW fuel cell system. Mirza [13] measured the performance of this 
membrane module and reported that $20-35 \%$ of water in the inlet wet air at 2.3 atm and $80^{\circ} \mathrm{C}$ ( $<80 \%$ relative humidity) could be transferred to the dry air at $2.5 \mathrm{~atm}$ and $80^{\circ} \mathrm{C}$. Under similar conditions, the water transfer rates in the enthalpy wheel humidifier were considerably higher $(50-70 \%)$.

Compactness (high transport flux), ease of packaging (planar rather than circular geometry), cost and durability are some of the requirements for water transport membranes and modules for automotive fuel cells. Whereas PFSA membranes fulfill most of these requirements for the water transport media, they fall short primarily on cost, and secondarily on durability, especially when they are made thin to increase performance and lower cost. Recently, Johnson et al $[14,15]$ have developed a composite water vapor transport membrane that overcomes both of these limitations. The basic composite structure shown in Fig. 1 consists of a very thin ionomer layer sandwiched between two microporous polymer layers. The ionomer layer provides the active water transport and acts as an impermeable barrier to prevent gas cross-over. The water transport rate can be engineered to be very high either through the use of a material that has very high inherent water transport rates (e.g., PFSA polymers), or by making it extremely thin (e.g., $<5 \mu \mathrm{m}$ ). The microporous layer provides three critical features: first it protects the thin ionomer layer from mechanical damage during handling; second, it confers strength to the thin layer allowing it to be more durable during use; and third, it offers a strong, protective support layer for placement of a macroporous gas diffusion layer.

The composite membrane has been incorporated in an innovative pleated planar membrane humidifier that is able to achieve automotive water transport and pressure drop requirements [15]. The pleated design utilizes existing low-cost, high-volume pleating equipment that is used to manufacture air filters for automotive and heating, ventilation and air conditioning applications. 
Although the pleated humidifier is a proven technology, further improvement in humidifier size, cost and performance is possible through the use of the composite membrane and optimizing the flow field channel design to take full advantage of its intrinsically high transport fluxes.

The purpose of this paper is to present a model that has been developed to characterize the performance of the composite membrane and the planar cross-flow humidifier assembled using this membrane. The emphasis here is on mechanisms and rates of water transport rather than cost and durability that are equally important. We use the model to identify first the sources of water transport resistances in the membrane and then the optimum operating conditions for achieving maximum transport flux in the humidifier module.

\section{Experimental}

\subsection{Composite Membranes (Gore)}

Composite membranes of silicone, low equivalent weight perfluorosulfonic acid (PFSA), divinyl benzene styrene polymer, polyvinyl alcohol, and polyurethane were prepared in multiple thicknesses using different types of expanded polytetrafluoroethylene (ePTFE) reinforcements in the composite structure [15]. Additionally, in order to reduce the material cost and improve performance, approaches were investigated to reduce the content of the expensive ionomer in the composite structures. Thicknesses of the ionomer layer in the composite ranged from as thin as $\sim 1 \mu \mathrm{m}$ up to about $10 \mu \mathrm{m}$. The optimal thickness appeared to be on the order of $5 \mu \mathrm{m}$, which uses a small amount of ionomer thus reducing cost, while simultaneously allowing acceptable processing. Although thinner layers are possible, it may be difficult to maintain a continuous hole-free layer with the required quality when ionomer layers are thinner than 3-5 $\mu \mathrm{m}$ or so. Samples of $18 \mu \mathrm{m}$ GORE-SELECT ${ }^{\circledR}$ membrane were obtained for use as a control. 
The use of a macroporous backer with the composites made in this study may or may not be essential but it is advantageous for handling. A range of potential macroporous backer materials were explored and a light, open polyester non-woven backer was identified as ideal. Its cost is low, it is very open so does not impact water transport significantly, it withstands the temperature excursions expected in the application, and can be readily laminated to the composite membrane. This material, an open PET (polyethylene terephthalate) nonwoven fabric, shows acceptable water transport performance. Durability testing in the module indicated that this material has little impact on either durability or water transport behavior, and, therefore, it was used in all module tests.

\subsection{Membrane Characterization (Gore)}

The membranes were characterized by measuring multiple properties including air permeance in wet and dry conditions, hot soak durability, and RH cycling durability. The water vapor transport rate was the primary screening tool for all samples.

Membrane samples were placed in a specially-designed dynamic test apparatus shown in Fig. 2a that minimizes pressure loss, and all resistances to water transport except that of the membrane. At a fixed temperature, a high humidity gas stream was applied to one side at high flow rate, and a low humidity gas at high flow is applied to the other. The humidities of the inlet and output streams were recorded and the water permeation rate per unit area was thus calculated. In order to determine the inherent cell resistance, samples of multiple layers are run under identical conditions and the inherent non-zero cell resistance is determined from the y-intercept after extrapolation to zero layer thickness. Alternatively, the permeance can be calculated directly from the slope of the measured rate versus layer thickness (see Fig. 3). In order to improve the 
precision, testing was performed at multiple different (high) flow rates on the dry and wet sides, thus giving semi-independent measurements of permeation rates.

Measuring the permeance of one sample using the dynamic test protocol took 3-4 days because it involves multiple flow rates, temperatures and individual tests on different layer thicknesses of the material. In an effort to increase testing throughput, we developed and implemented a fast screening test for measurement of permeance. This test is based upon ISO standard 15496 [16], "Measurement of Water Vapor Permeability of Textiles for Purpose of Quality Control". This test protocol, used extensively in the fabrics industry as a quality control tool, had to be modified slightly to achieve more precise values for the very high permeance materials being investigated. The advantage of this test is that it is possible to measure the permeance of a sample in several hours, instead of 3-4 days with the dynamic test procedure.

Initially, the measurement was made at room temperature instead of the typical humidifier use temperature of $80^{\circ} \mathrm{C}$. An example of the test setup is shown in Fig. $2 \mathrm{~b}$ and the typical results are included in Fig. 3. Although this test is acceptable in terms of speed and consistency, the room temperature data did not show the same relative difference in permeance between materials observed in the dynamic water permeance test. For example, M311.05 was only about 20\% higher in permeance in the room temperature pseudo static test (Fig. 4a), while the dynamic test at $80^{\circ} \mathrm{C}$ showed it to be nearly twice as high (Fig. $4 \mathrm{~b}$ ). Therefore, we chose to modify the ISO standard so we could perform the test at $80^{\circ} \mathrm{C}$ instead of room temperature.

The modified pseudo-static test we eventually arrived at after extensive experimentation is illustrated in Fig. 2c. The sample to be tested is placed on a fixed temperature water bath, which fixes the relative humidity (RH) on one side of the sample. The RH on the other side is fixed by a saturated salt solution, sodium iodide, which has a constant $\mathrm{RH}$ at $80^{\circ} \mathrm{C}$ of $\sim 23 \%$. The cup 
containing the saturated salt is pre-equilibrated at $80^{\circ} \mathrm{C}$ in an oven prior to the test. During the test, the salt solution is separated from the sample by a microporous ePTFE membrane that allows vapor through it, but does not let liquid through it. There is also an ePTFE membrane on the water bath so that the sample is never in contact with liquid water. The sample is tested for a fixed time during which water transports from the high RH bath into the drier cup. Thus, the cup picks up weight. The cup weight before and after gives the weight gain, and the flux through the sample is calculated from that weight gain, the time on the test, and the area of the cup opening. Because the RH is constant over the entire area of the sample under test for the entire test time, this is nearly a static Fick's first law test. But, because there is some initial short time (relative to the test time) during which the materials come to steady state, it is more properly called a pseudo steady-state test.

A comparison of the measured permeance from the dynamic and the pseudo-static tests at $80^{\circ} \mathrm{C}$ is shown in Fig. $4 \mathrm{c}$ for a range of different materials. There is reasonable agreement between the two different test protocols for materials with permeances above 20,000 GPU ( 1 GPU=7.5x $10^{-16}$ $\left.\mathrm{m} \cdot \mathrm{s}^{-1} \cdot \mathrm{Pa}^{-1}\right)$. The test parameters, for example the time of the test and the test area, were optimized for the high transport materials that were of most interest. The differences observed for the lower permeance materials most likely results from the fact that those materials will take longer to reach steady state than the high permeance materials. Therefore, the conditions during the test are moving away from the assumption of "static" conditions, thereby introducing errors when the Fick's first law analysis is used. Of course, the test could be modified by using a different test time or different test areas for these low permeance materials, but this was not done because the focus of the work was on high permeance materials. The particular test conditions were chosen to optimize the test speed and reproducibility for these higher permeance materials. 
A range of homogenous films were examined to narrow down the choice of appropriate ionomers to investigate in composite structures. Not surprisingly, fluoropolymer ionomers, and long side chain perfluorosulfonic acid (PFSA) ionomers in particular, had the highest permeance. Within this class of material, the permeance increased with decreasing equivalent weight of the ionomer, again as expected from the literature. The magnitude of the increase was not dramatic, though, increasing on the order of $10-20 \%$ as the equivalent weight decreased from 900 to $\sim 700$. A number of hydrocarbon ionomers were examined as well. This class of ionomers generally had much lower water transport, with the sulfonated aromatics higher than non-sulfonated aromatics, and non-sulfonated aromatics higher than straight chain polymers. The permeance of the best of the hydrocarbons was one half to one third of the PFSA materials in composite form (Figs. $4 \mathrm{~b}$ and 4d). As a result, we focused primarily on the PFSA ionomers in order to get the highest permeance composites. We felt that higher transport rates would be required in order to make a module that had the required water transport characteristics and was small enough to meet the automotive size restrictions.

We also investigated the use of either thinner ionomer layers, or more open ePTFE outer layers. It is possible to increase performance either by using more open, permeable ePTFE layers in the composite, or by using a thinner ionomer layer. In the case of the thinner ionomer layers, the increase in permeance is not linear with ionomer layer thickness, i.e., halving the ionomer layer thickness does not increase permeance by a factor of two as might be expected for a homogeneous film. This result is not completely unexpected because the resistance to water transport in the microporous ePTFE is a substantial fraction of the total resistance in the composite. Thus, decreasing the resistance to water transport in the ionomer layer by making that layer thinner will increase the permeance, but not by as large a factor as in a homogeneous film 
because of the water transport resistance of the two layers of the ePTFE that are unchanged. Correspondingly, decreasing the thickness or increasing the pore size/porosity of the ePTFE layers increases the composite permeance, and can have a somewhat larger effect because there are two layers of ePTFE in the composite.

For example, during these tests the standard construction material of $\sim 5 \mu \mathrm{m}$ of PFSA ionomer sandwiched between two layers of a "standard" ePTFE material, identified in Fig. 4d as "SC", yielded permeance $\sim 3.5$ times that of the control GORESELECT ${ }^{\circledR}$ membrane (GSM). By changing the type of ePTFE used to one that is lighter, and therefore thinner and/or more open, the relative permeance increased to 5 to 6 times that of the GSM. On the other hand, by changing the nature of the ionomer layer between the ePTFE layers to a less conductive material, the relative permeance is decreased significantly to the level of the GSM or even lower as shown with the "SC-Alternate inner layer 1" and "SC-Alternate inner layer 2" samples. Finally, as expected the hydrocarbon (HC) ionomer based materials have much poorer performance relative to the GSM.

We did test the limits of how thin the inner ionomer layer in the composite structure can be made. Making it much thinner, for example $1 \mu \mathrm{m}$ thick, increases the water transport significantly (Fig. 4a). There is a practical limit to how thin an ionomer we are able to use in the composite structure. As that layer gets thinner and thinner, the likelihood of a defect increases. Because the product may ultimately be used in automotive applications where 6-sigma quality is required, we chose to focus on ionomer layers of $5 \mu \mathrm{m}$ or higher. At $5 \mu \mathrm{m}$ the ionomer is thin enough to give the composite high permeance and acceptable durability, but still can be manufactured in high volume to meet automotive quality standards. A thin $5 \mu \mathrm{m}$ ionomer layer is also significantly 
less expensive than the lower permeance homogeneous membrane of ionomer that would have to be on the order of $25-30 \mu \mathrm{m}$ to be manufacturable and durable.

In the same way, although we made many composites with very thin and/or light ePTFE outer layers, as these layers become too thin or light, their ability to protect the inner ionomer layer could decrease. Therefore, we focused on ePTFE layers that were open enough to give high composite permeability, and also thick enough to provide protection to the ionomer layer, while also providing acceptable handling during manufacturing and subsequent module construction. Other open microporous layers, for example polyethylene or polypropylene were considered but ultimately rejected because they would likely not hold up to higher automotive use temperatures and/or RH cycling conditions.

\subsection{Humidifier Module (dPoint)}

Conceptual design of a compact humidifier housing, selection of a vaned concept using computational fluid dynamics (CFD), and validation of this concept using a machined ABS housing were accomplished in the early stages. Flow variance was found to be about $6 \%$ using CFD analysis. Based on the subscale validation, it was projected that the vaned housing in combination with the selected cartridge design would very likely meet all the targets of the project. Interestingly, it was found experimentally that the vanes themselves had an insignificant effect on performance, and they would present significant challenges to the manufacturing of the housing.

Concurrently, flow distribution and performance of commercial energy recovery ventilator (ERV) systems were analyzed using CFD and an analytical model. It was concluded that vertical flow distribution in a crossflow exchanger had a greater impact on performance than lateral distribution. This explains why the vanes in the selected compact fuel cell humidifier housing 
had little impact-the important feature was the tapered feature adjacent to the inlet of the humidifier cartridge ensuring satisfactory vertical flow distribution.

\subsubsection{Auxiliary Humidity Exchanger Material Choice}

Based on these findings, the housing was redesigned such that it could be cast or injection molded in two parts, as these are known to be very low cost manufacturing techniques. Based on finite element analysis (FEA) with the expected operating temperatures and pressures, it was decided that metals would be a more suitable housing material than polymers. The die casting of aluminum alloy A380 was tentatively selected. Since this material has the potential to contaminate fuel cell stacks, it is envisioned that the housing will be coated such that ionic contaminants cannot leach out (see Fig. 5a).

\subsubsection{Humidity Exchanger Characterization}

The analysis of different humidifier designs and energy recovery ventilator (ERV) cores, and heat exchangers literature review, yielded approximately 40 module concepts that could meet the cost and transport targets for the most severe module application. Focus was then on the ten most promising of these, where small prototype builds using different flow fields were completed. These results coupled with the CFD modeling led to the following conclusions:

- Small linear channels yield the best transfer per pressure drop;

- Small pitches in the flow field make the volume requirements easier to meet, although there are potential manufacturing cost disadvantages (see Fig. 5b);

- Cross-flow designs have many desirable features and fewer drawbacks than other design alternatives.

The models that were used to characterize the performance of the humidifier were:

- Analytical 
- module control volume calculator based on stack conditions

- CFD Analysis

○ mass transfer and pressure drop of flow field features

○ housing flow distribution

- Experimental

o pressure drop and mass transfer tests of 23 flow field designs

$\circ$ four subscale cartridges tested in two housings

- Hybrid Analytical-Experimental Calculator

- module architecture and characteristic dimensions input

o pressure drop calculated using analytical methods

o performance estimated using results of module tests

Using these learnings, the first cross-flow humidifier module was constructed as a subscale 10 $\mathrm{cm}^{2}$ module that uses $0.4 \mathrm{~m}^{2}$ of membrane in 40 layers. The flow fields use a $0.8 \mathrm{~mm}$ pitch in line with the results described above. Results from limited initial single cell testing showed promising results. For scaling to a full scale module, the volume and water transfer characteristics were met with $2 \mathrm{~m}^{2}$ of membrane. These preliminary results were confirmed in further testing when a full scale humidifier was built and tested as described below.

\subsection{Module Testing (Ford)}

The performance of the full-scale module was characterized in a fully instrumented facility for testing cathode humidifier modules under realistic automotive conditions. This facility is capable of achieving very high flow rates, up to 3500 SLPM, and elevated temperatures, $65-80{ }^{\circ} \mathrm{C}$. It has the ability to accurately and controllably humidify these hot, high-flow gas streams and is instrumented rapidly measure $\mathrm{RH}$ at multiple locations. 
The testing was completed for flow rates between 500 and 3500 SLPM and temperature at $65^{\circ} \mathrm{C}$ Independent sensors measured the flow rates, dew points (or equivalently, $\mathrm{RH}$ ), temperatures, and pressures at multiple locations at the inlet of the primary (dry side) and secondary (wet side) of the humidifier module. The raw data was converted to appropriate pressures, flows and water contents, and then averaged to obtain the relevant values. Table 1 lists the inlet pressure and RH conditions in Test Series A, B, C and D with different flow rates. Test Series M was formulated to validate data over a wide range of module operating conditions.

\section{Theoretical}

Figure 5c shows the reference framework of the model. The coordinate system uses $\mathrm{x}$ as the membrane thickness direction, $\mathrm{y}$ as the axial direction of wet flow, and $\mathrm{z}$ as the axial direction of dry flow. The model framework consists of five regions representing the wet gas channel, wet ePTFE layer, ionomer, dry ePTFE layer, and dry gas channel. The primary mechanisms for heat and mass transfer are convection in the gas channels, gas phase diffusion in the microporous ePTFE layers, and solid phase diffusion in the impervious ionomer layer.

\subsection{Ionomer Phase}

It is customary to describe water transport in the ionomer in terms of $\lambda$ (water uptake), defined as the moles of water per gram equivalent of the polymer [17]. Since the ionomer film is only a few micrometers thick, water transport in the planar directions can be ignored. The following diffusion equation then may be used to determine the $\lambda$ profile in the thickness direction.

$$
\frac{\partial \lambda}{\partial t}=\frac{\partial}{\partial x}\left(D_{\lambda} \frac{\partial \lambda}{\partial x}\right)
$$

The temperature profile across the ionomer phase can be determined by solving the following energy equation that includes contribution of water transport to heat transfer but ignores the effects of phase changes. 


$$
\frac{\partial}{\partial t}\left[\rho_{m} i_{m}+\left(\frac{\rho_{m} M_{v}}{E_{m}}\right) \lambda i_{v}\right]=\frac{\partial}{\partial x}\left(k_{m} \frac{\partial T_{m}}{\partial x}\right)+\frac{\partial}{\partial x}\left[\left(\frac{\rho_{m} M_{v}}{E_{m}}\right)\left(D_{\lambda} \frac{\partial \lambda}{\partial x}\right) i_{v}\right]
$$

Equation (2) can be rearranged to write the energy equation in terms of the effective specific heat and thermal conductivity of the ionomer.

$$
\begin{aligned}
& \rho_{m} c_{p m}^{e f f} \frac{\partial T_{m}}{\partial t}+M_{v} J_{m} c_{p v} \frac{\partial T_{m}}{\partial x}=\frac{\partial}{\partial x}\left(k_{m} \frac{\partial T_{m}}{\partial x}\right) \\
& c_{p m}^{e f f}=c_{p m}+\left(\frac{M_{v} \lambda}{E_{m}}\right) c_{p v}
\end{aligned}
$$

where the water transport flux $\left(J_{m}\right)$ is defined as

$$
J_{m}=-\left(\frac{\rho_{m}}{E_{m}}\right) D_{\lambda} \frac{\partial \lambda}{\partial x}
$$

At steady state, Eq. (4) can be integrated analytically to obtain an expression for the ionomer resistance $\left(R_{m}\right)$ to water vapor transport as follows.

$$
\begin{aligned}
& J_{m}=\left(\frac{\rho_{m}}{E_{m} \delta_{m}}\right) \int_{\lambda_{d}}^{\lambda_{w}} D_{\lambda} d \lambda \\
& J_{m}=\frac{C_{v w}^{m}\left(\lambda_{w}\right)-C_{v d}^{m}\left(\lambda_{d}\right)}{R_{m}} \\
& R_{m}=\left(\frac{E_{m} \delta_{m}}{\rho_{m}}\right)\left[\frac{C_{v w}^{m}\left(\lambda_{w}\right)-C_{v d}^{m}\left(\lambda_{d}\right)}{\lambda_{w w}}\right] \\
& \int_{\lambda_{d}} D_{\lambda} d \lambda
\end{aligned}
$$

\section{2 ePTFE Phase}

Neglecting water transport in the planar directions, the following are the equations for molar concentrations and temperature across the thin, quiescent, microporous ePTFE layers adjacent to the wet and dry channels.

$$
\frac{\partial C_{v w}^{e}}{\partial t}+\frac{\partial\left(u_{w} C_{v w}^{e}\right)}{\partial x}=\frac{\partial}{\partial x}\left(D_{v w}^{e} \frac{\partial C_{v w}^{e}}{\partial x}\right)
$$




$$
\begin{aligned}
& \rho_{w}^{e} c_{p w}^{e} \frac{\partial T_{w}^{e}}{\partial t}+\left(u_{w} C_{v w}^{e}+J_{w}^{e}\right) M_{v} c_{p v} \frac{\partial T_{w}^{e}}{\partial x}=\frac{\partial}{\partial x}\left(k_{w}^{e} \frac{\partial T_{w}^{e}}{\partial x}\right) \\
& J_{w}^{e}=-D_{v w}^{e} \frac{\partial C_{v w}^{e}}{\partial x} \\
& \frac{\partial C_{v d}^{e}}{\partial t}+\frac{\partial\left(u_{d} C_{v d}^{e}\right)}{\partial x}=\frac{\partial}{\partial x}\left(D_{v d}^{e} \frac{\partial C_{v d}^{e}}{\partial x}\right) \\
& \rho_{d}^{e} c_{p d}^{e} \frac{\partial T_{d}^{e}}{\partial t}+\left(u_{d} C_{v d}^{e}+J_{d}^{e}\right) M_{v} c_{p v} \frac{\partial T_{d}^{e}}{\partial x}=\frac{\partial}{\partial x}\left(k_{d}^{e} \frac{\partial T_{d}^{e}}{\partial x}\right) \\
& J_{d}^{e}=-D_{v d}^{e} \frac{\partial C_{v d}^{e}}{\partial x}
\end{aligned}
$$

\subsection{Wet Gas Flow}

Using plug flow representation, the following are the equations for changes in the molar concentration of water vapor, gas temperature and momentum in the wet channels (half height $\left.L_{w}\right)$ due to heat transfer, $\left(q_{w}\right)$, friction $\left(\tau_{w}\right)$, and mass transfer $\left(J_{w}\right)$.

$$
\begin{aligned}
& \frac{\partial C_{v w}}{\partial t}+\frac{\partial\left(v_{w} C_{v w}\right)}{\partial y}=-\frac{J_{w}}{L_{w}} \\
& \rho_{w} \frac{\partial v_{w}}{\partial t}+\rho_{w} v_{w} \frac{\partial v_{w}}{\partial y}=-\frac{\partial P_{w}}{\partial y}-\frac{\tau_{w}}{L_{w}} \\
& \rho_{w} c_{p w} \frac{\partial T_{w}}{\partial t}+\rho_{w} v_{w} c_{p w} \frac{\partial T_{w}}{\partial y}=-\frac{q_{w}}{L_{w}}
\end{aligned}
$$

\subsection{Dry Gas Flow}

As above, the following are the equations for changes in the molar concentration of water vapor, momentum and gas temperature in the dry channels (half height $\left.L_{d}\right)$ due to heat transfer, $\left(q_{d}\right)$, friction $\left(\tau_{d}\right)$, and mass transfer $\left(J_{d}\right)$.

$$
\frac{\partial C_{v d}}{\partial t}+\frac{\partial\left(w_{d} C_{v d}\right)}{\partial z}=\frac{J_{d}}{L_{d}}
$$


$\rho_{d} \frac{\partial w_{d}}{\partial t}+\rho_{d} w_{d} \frac{\partial w_{d}}{\partial z}=-\frac{\partial P_{d}}{\partial z}-\frac{\tau_{d}}{L_{d}}$

$\rho_{d} c_{p d} \frac{\partial T_{d}}{\partial t}+\rho_{d} w_{d} c_{p d} \frac{\partial T_{d}}{\partial z}=\frac{q_{d}}{L_{d}}$

\subsection{Method of Solution}

The foregoing set of equations for steady flow has been solved numerically for co-flow $(z=y)$, counter-flow $(z=-y)$ and cross-flow humidifiers. The flow domain (i.e., wet and dry channels) was divided in to a grid that consists of $J$ wet sub-channels and $K$ dry sub-channels. The numerical solution is particularly convenient if the $J$ wet sub-channels are treated as perfectly parallel and unmixed, as also the $K$ dry sub-channels.

For cross-flow, the integration starts from the corner where the wet and dry streams enter the humidifier, $j=1, k=1$. The set of equations, Eq. (8), for wet flow is integrated by marching in the y-direction along $j=1$ to $j=J$ for the first sub-channel $(k=1)$. For each grid, the set of equations, Eq. (9), for dry flow is simultaneously integrated for the dry sub-channels, $k=1$ to $k$ $=K$ and $j=1$. The solution then shifts to the second wet sub-channel, $j=2$, and these steps are repeated until the solution is obtained for the last wet sub-channel, $j=J$.

The extension of the above algorithm to co-flow configuration is quite straightforward. Iterations, however, are needed for counter-flow configuration, since one of the flow streams must be integrated in the direction counter to the flow and the exit conditions are not known.

We find that the solution is robust if Eqs. (8) and (9) are discretized using an upwind finitedifference scheme and the resulting algebraic equations are solved simultaneously for each grid point using a non-linear equation solver.

Note that for steady flow, Eqs (1) and (3) can be solved analytically if the boundary values of $\lambda\left(\lambda_{w}\right.$ and $\left.\lambda_{d}\right)$ and $T_{m}\left(T_{w}^{s}\right.$ and $\left.T_{d}^{s}\right)$ are known. Similarly, Eqs (6) and (7) can be solved 
analytically for water vapor concentration and temperature profiles in the dry and wet ePTFE layers.

Finally, the solutions for the wet channel, wet ePTFE layer, ionomer phase, dry ePTFE layer and the dry channel are linked through the following boundary conditions.

$$
\begin{aligned}
& J_{w}=K_{w}\left(C_{v w}-C_{v w}^{e}\right)=K_{w}^{e}\left(C_{v w}^{e}-C_{v w}^{s}\right)=\beta_{w}\left(\lambda_{w}^{s}-\lambda_{w}\right)=-\left(\frac{\rho_{m}}{E_{m}}\right)\left(D_{\lambda} \frac{\partial \lambda}{\partial x}\right) \\
& q_{w}=U_{w}\left(T_{w}-T_{w}^{e}\right)=U_{w}^{e}\left(T_{w}^{e}-T_{w}^{s}\right)=-k_{m}^{e f f} \frac{\partial T_{m}}{\partial x} \\
& J_{d}=K_{d}\left(C_{v d}^{e}-C_{v d}\right)=K_{d}^{e}\left(C_{v d}^{s}-C_{v d}^{e}\right)=\beta_{d}\left(\lambda_{d}-\lambda_{d}^{s}\right)=-\left(\frac{\rho_{m}}{E_{m}}\right)\left(D_{\lambda} \frac{\partial \lambda}{\partial x}\right) \\
& q_{d}=U_{d}\left(T_{d}^{e}-T_{d}\right)=U_{d}^{e}\left(T_{d}^{s}-T_{d}^{e}\right)=-k_{m}^{e f f} \frac{\partial T_{m}}{\partial x}
\end{aligned}
$$

In the above equation, $1 / \beta_{w}$ and $1 / \beta_{w}$ denote the interfacial resistances to mass transfer at ePTFE-ionomer junctions. At steady state,

$$
\begin{aligned}
& J_{w}=J_{d} \\
& q_{w}=q_{d}
\end{aligned}
$$

\section{Results and Discussion}

\subsection{Mass Transfer Resistances}

Equations (9) and (10) can be used to define an overall mass transfer resistance $(R)$ such that at steady state

$$
J_{w}=J_{d}=\frac{\left(C_{v w}-C_{v d}\right)}{R}
$$


Here, $R$ is composed of in-series resistances to water vapor transport through the wet gas channel $\left(R_{w}\right)$, wet ePTFE layer $\left(R_{w}^{e}\right)$, wet interface of the ionomer $\left(R_{i w}\right)$, ionomer layer $\left(R_{m}\right)$, dry interface of the ionomer $\left(R_{i d}\right)$, dry ePTFE layer $\left(R_{d}^{e}\right)$, and dry gas channel $\left(R_{d}\right)$.

$$
\begin{aligned}
& R=R_{w}+R_{w}^{e}+R_{i w}+R_{m}+R_{i d}+R_{d}^{e}+R_{d} \\
& R_{w}=1 / K_{w}=\delta_{w} / D_{v w} \\
& R_{w}^{e}=1 / K_{w}^{e}=\delta_{e} / D_{v w}^{e} \\
& R_{i w}=\frac{1}{\beta_{m}}\left(\frac{C_{v w}^{s}-C_{v w}^{m}}{\lambda_{w}^{s}-\lambda_{w}}\right) \\
& R_{m}=\left(\frac{E_{m} \delta_{m}}{\rho_{m}}\right)\left(\frac{C_{v w}^{m}-C_{v d}^{m}}{\lambda_{w}}\right) \\
& \int_{\lambda_{d}} D_{\lambda} d \lambda \\
& R_{i d}=\frac{1}{\beta_{d}}\left(\frac{C_{v d}^{s}-C_{v d}^{m}}{\lambda_{w}^{s}-\lambda_{w}}\right) \\
& R_{d}^{e}=1 / K_{d}^{e}=\delta_{e} / D_{v d}^{e} \\
& R_{d}=1 / K_{d}=\delta_{d} / D_{v d}
\end{aligned}
$$

A step-wise procedure was used to estimate the individual resistances to the overall water vapor transport. These steps are briefly described below.

As a first step, the ionomer resistance $\left(R_{m}\right)$ to water transport can be determined from Eq. (5) if we know $D_{\lambda}\left(\mathrm{m}^{2} \cdot \mathrm{s}^{-1}\right)$ as function of $\lambda$ and $\lambda$ as function of the water vapor concentration at the interface. We used the following equations for $D_{\lambda}$ and $\lambda[17,18]$.

$$
\begin{aligned}
& D_{\lambda}(T)=D_{\lambda}(303 K) \exp \left[2416\left(\frac{1}{303}-\frac{1}{T}\right)\right] \\
& D_{\lambda}(303 K)=\left(0.23 \lambda^{3}-0.58 \lambda^{2}+0.76 \lambda-0.356\right) 10^{-10}, \lambda<3
\end{aligned}
$$




$$
\begin{aligned}
& D_{\lambda}(303 K)=\left(1.04+378.75 \lambda^{-4.84}\right) 10^{-10}, \lambda \geq 3 \\
& \lambda=23.82 a^{4}-28.5 a^{3}+8.36 a^{2}+5.92 a+0.04
\end{aligned}
$$

In the above equation, $a$ is the activity (same as RH) defined as the ratio of water vapor concentration to its value at saturation.

Next, we estimated the boundary layer resistance to vapor mass transport in the static and dynamic tests from the permeance measured for one to four layers of sandwich membranes stacked together. Figure 3 presents a linear regression of the data; extrapolation of this data to zero number of layers provides a measure of the boundary layer resistance to vapor mass transport $\left(R_{w}+R_{d}\right)$. Equation (13) was used to determine the boundary layer thickness from $R_{w}$ and $R_{d}$. We used the Chapman-Enskog formula for binary diffusivity of $\mathrm{H}_{2} \mathrm{O}-\mathrm{N}_{2}$ and $\mathrm{H}_{2} \mathrm{O}-\mathrm{O}_{2}$ mixtures and the Stefan-Maxwell equation for the effective diffusivity of water vapor $\left(D_{v w}\right.$ and $\left.D_{v d}\right)$ in wet and dry gases.

The slope of the linear regression line in Fig. 3 is a measure of the combined resistance of one layer of membrane $\left(R_{l}\right)$.

$$
R_{1}=R_{w}^{e}+R_{i w}+R_{m}+R_{i d}+R_{d}^{e} .
$$

Knowing the dependence of $R_{m}$ on ionomer thickness, we scaled the permeance measured for 18$\mu \mathrm{m}$ Select membrane to $5-\mu \mathrm{m}$ layer thickness. The difference between the resistances of the M311.05 membrane and the scaled $18-\mu \mathrm{m}$ Select membrane (see Fig. 4a and $4 \mathrm{~b}$ ) is a measure of the combined resistance of the wet and dry ePTFE layers $\left(R_{w}^{e}+R_{d}^{e}\right)$. Knowing $R_{w}^{e}$ and $R_{d}^{e}$, we used Eq. (13) to determine the effective diffusivity of water vapor in the micro-porous ePTFE layer, and derived an empirical factor $\left(f^{e}\right)$ that accounts for the effect of porosity and tortuosity on $D_{v w}^{e}$ and $D_{v d}^{e}$. 
$D_{v w}^{e}=f^{e} D_{v w}$

$D_{v d}^{e}=f^{e} D_{v d}$

Finally, knowing $R_{l}, R_{m}$, and $\left(R_{w}^{e}+R_{d}^{e}\right)$, we estimated the combined interfacial resistance $\left(R_{i w}+R_{i d}\right)$ from Eq. (15) and the kinetic constants $\beta_{w}$ and $\beta_{d}$ from Eq. (13). These estimated constants are listed in Table 2.

Figure 6a presents the breakdown of the estimated mass transfer resistances in the static and dynamic tests. To the first order, the external boundary layer, interfacial and ePTFE resistances only depend on temperature and vapor concentrations (pressures and relative humidities), while the ionomer resistance also depends on the thickness of the ionomer layer.

Figures (6b) and (6c) compare the modeled with measured water vapor transport fluxes. Whereas the mass transfer resistances are lower in the room temperature static tests, the vapor transport fluxes are almost five times higher in the $80^{\circ} \mathrm{C}$ dynamic tests. Also, reducing the ionomer layer thickness from $18 \mu \mathrm{m}$ in Gore-Select membrane to $5 \mu \mathrm{m}$ in M311.05 membrane results in nearly $50 \%$ increase in the vapor transport flux at $80^{\circ} \mathrm{C}$. Further reduction in the ionomer layer thickness to $1 \mu \mathrm{m}$ in M311.05 membrane results in a correspondingly smaller increase in vapor transport flux because of the constant external boundary layer, interfacial and ePTFE resistances.

\subsection{Model Calibration}

We used Eqs (1) - (11) with the empirical constants derived above from the static and dynamic tests to analyze the experimental data for the module. The only change was to use the appropriate Nusselt number correlation for heat and mass transfer and friction factors to determine $U_{w}, U_{d}$, $K_{w}, K_{d}, \tau_{w}$ and $\tau_{d}$ for laminar flow in rectangular passages with triangular inserts [19].

Figure 7 presents illustrative contour plots of the modeled results, showing changes in the relative humidities of the dry and wet streams. As expected, the highest level of relative humidity 
in the exiting dry stream is in the vicinity of the corner adjacent to the inlet of the wet stream. However, the lowest level of relative humidity in the exiting wet stream is not in the vicinity of the corner adjacent to the inlet of the dry stream. This is because $D_{\lambda}$ is quite small if $\lambda<<3$, see Eq. (14).

Figure 8 presents water vapor transport flux as a function of $\mathrm{RH}$ at wet inlet for different flow rates, wet inlet temperatures and operating pressures. Included as solid symbols are the experimental data and as open symbols the modeled results for the actual conditions in Test Series A, B, C and D that differ slightly from the conditions used in the model to generate the solid lines. We see quantitative agreement between the model results and experimental data. Figure 8 shows that the higher the inlet $\mathrm{RH}$, or the lower the operating pressure, the greater is the amount of water vapor in the inlet wet stream, and the higher is the water vapor transport flux (see also the discussion in Section 4.4). The transport flux also increases at higher flow rates. Figure 9 is a reinterpretation of the above results on the basis of water transfer effectiveness defined as the fraction of water in the inlet wet stream that is transported to the dry outlet stream. Unlike the transport flux, the effectiveness decreases at higher flow rates (at constant pressure) and increases as the operating pressure is raised (at constant flow rate).

Figure 10 is parity plot that compares the modeled with measured water transport fluxes and water transfer effectiveness. It includes data from all tests including Test Series $M$ in which multiple operating conditions were varied at the same time. We conclude that over the range of experimental pressures, temperatures, relative humidities and flow rates, the model shows correct behavior with a degree of correlation $\left(\mathrm{R}^{2}\right)$ of 0.993 . 


\subsection{Assessment of Performance}

The inset in Fig. 11 stipulates a set of conditions for which it is desired that a humidification module for transportation fuel cells should transfer $5 \mathrm{~g} . \mathrm{s}^{-1}$ water vapor while reaching a flux of $4.2 \mathrm{~g} \cdot \mathrm{m}^{-2} \cdot \mathrm{s}^{-1}$. We used our model to determine the active membrane area and performance of the cross-flow humidifier for these specifications of inlet pressures, temperatures, flow rates and relative humidities of the wet and dry gases. The model indicates that the water flux in the planar humidifier with M311.05 membrane is about 25\% lower than the target under these conditions. We conducted a parametric analysis and found that the target flux can be reached if a heat exchanger upstream of the humidifier is used to cool the dry air to $65^{\circ} \mathrm{C}$ at inlet. The analysis also shows that the water vapor flux reaches a peak value of $5.5 \mathrm{~g} \cdot \mathrm{m}^{-2} \cdot \mathrm{s}^{-1}$ if the dry air is further cooled to $40^{\circ} \mathrm{C}$ at inlet.

The water vapor transport flux is a function of heat and mass transfer. The flux is limited by the difference in relative humidities of the two streams (actually $\lambda_{w}-\lambda_{d}$ ) across the ionomer and by the gradient in partial pressures in the ePTFE layers and the gas channels. The flux is high if the wet stream is maintained at close to the saturated condition by manipulating its temperature and if the dry stream is not allowed to approach saturation. Thus, there is an optimum dry air inlet temperature $\left(T_{d}^{i n}\right)$ at which the flux is the highest $\left(45^{\circ} \mathrm{C}\right.$ for the conditions in Fig. 11). Raising $T_{d}^{i n}$ above this optimum temperature reduces the flux because the dry stream does not sufficiently cool the wet stream so that the wet stream RH drops below $100 \%$. Lowering $T_{d}^{\text {in }}$ below this optimum temperature reduces the flux because the wet stream does not sufficiently heat the dry stream so that the dry stream RH approaches $100 \%$. 


\subsection{Humidifier Performance}

Figure 12 presents the modeled water flux as function of the operating pressure and the approach dew point temperature $\left(\Delta T_{d p}\right)$ defined as the difference between the dew points of the inlet wet stream and the outlet dry stream. The results are for saturated inlet wet stream at $85^{\circ} \mathrm{C}$ if the operating pressure is $2.5 \mathrm{~atm}$ and $75^{\circ} \mathrm{C}$ if it is $1.5 \mathrm{~atm}$. The results indicate that depending on the approach dew point temperature, water flux can be 10-30\% higher with counter-flow than with cross-flow. Other factors, such as manufacturability, pressure drops, compactness and cost, however, may favor cross-flow over the counter-flow configuration.

The water vapor transport flux in Fig. 12 is quite sensitive to the approach dew point temperature. As expected, the lower the approach dew point temperature, the smaller is the flux. The results also show that the optimum temperature for maximum flux increases if $\Delta T_{d p}$ is reduced or if the wet inlet temperature is raised.

The water vapor transport flux in Fig. 12 increases with increase in saturated wet gas inlet temperature because of the exponential dependence of saturation pressure on temperature. Also, the diffusivity of water vapor increases with temperature, $D_{v} \propto T^{1.5}$ in Chapman Enskog equation, and the water diffusivity in the ionomer $\left(D_{\lambda}\right)$ has slight temperature dependence $(2.4$ $\left.\mathrm{kJ} \cdot \mathrm{mol}^{-1}\right)$.

At constant temperature, $100 \%$ wet stream $\mathrm{RH}$, and specified approach dew point temperature, the water vapor transport flux shows only weak pressure dependence since $C_{v} D_{v}$ and $D_{\lambda}$ are independent of pressure.

Figure 13 is a generalization of the results in Fig. 12. It indicates that the optimum approach temperature $\left(\Delta T^{i n}=T_{w}^{i n}-T_{d}^{i n}\right)$ for maximum water vapor transport flux increases almost linearly with the approach dew point temperature in cross-flow configuration, but there is an optimum 
$\Delta T^{\text {in }}$ if the configuration is counter-flow. It also indicates that for optimum $\Delta T^{\text {in }}$, the water vapor transport flux in cross-flow can approach within 5\% of the flux in counter-flow.

Figure 13 indicates that the water vapor transport flux levels out and may even decrease as the approach dew point temperature is raised above $20-25^{\circ} \mathrm{C}$. This is because raising $\Delta T_{d p}$ beyond 20-35 ${ }^{\circ} \mathrm{C}$ results in $\lambda_{d}$ dropping below 3 , so that $D_{\lambda}$ decreases and the ionomer resistance to mass transfer increases.

\section{Summary and Conclusions}

Pending availability of high-temperature membranes for polymer electrolyte fuel cells, most high power density stacks for automotive applications currently require that the inlet cathode air be externally humidified for extended stack durability and acceptable performance. Composite membrane M311.05, described in this work, satisfies many of the requirements for external humidification: compactness resulting from high WVT flux, ease of packaging as it can be pleated for use in a planar cross-flow humidifier, cost and durability.

We have identified and characterized the sources of mass transfer resistance in the M311.05 composite membrane. For the conditions of the modified dynamic ASM test at $80^{\circ} \mathrm{C}$, our transport model indicates that the mass transfer resistances in the external boundary layers, ionomer interfaces and the ionomer layer are of comparable magnitude while the resistance in the ePTFE microporous layers is negligible. Experimental data and the model show a significant $60 \%$ reduction in mass transfer resistance when the ionomer thickness is decreased from $18 \mu \mathrm{m}$ in the conventional membranes to $5 \mu \mathrm{m}$ in the M311.05 composite membrane. The model suggests that further decreasing the ionomer thickness to $1 \mu \mathrm{m}$ in M311.01 should result in $<20 \%$ marginal reduction in mass transfer resistance but may exacerbate the durability of ionomer. In this regard, M311.05 may be an optimum choice of membrane when balancing the 
advantages of compactness and cost saving with issues of ionomer durability and limited membrane lifetime.

We have developed a finite-difference flow model that incorporates the vapor transport model used to investigate the mass transfer resistances of M311.05 membrane in static and dynamic tests. The flow model was validated against experimental data for vapor transport in a planar cross-flow module with pleated M311.05 membranes of $2 \mathrm{~m}^{2}$ active area. Over the range of experimental pressures, temperatures, relative humidities and flow rates, the flow model shows correct behavior with a degree of correlation $\left(\mathrm{R}^{2}\right)$ of 0.993 . Both the model and experimental data show that WVT flux in the module increases at higher inlet relative humidity of the wet stream, higher flow rates and lower pressures, but the mass transfer effectiveness is higher at lower flow rates and higher pressures.

We used the model to investigate the performance for a set of conditions (see the inset in Fig. 11) for which a humidification module for transportation fuel cells should transfer 5 g.s ${ }^{-1}$ water vapor while reaching a flux of $4.2 \mathrm{~g} \cdot \mathrm{m}^{-2} \cdot \mathrm{s}^{-1}$. Our model indicates that WVT in the planar humidifier with M311.05 membrane is about 25\% lower than the target under these conditions, but the target flux can be reached if the dry air inlet temperature is lowered to $65^{\circ} \mathrm{C}$. The analysis also shows that WVT reaches a peak value of $5.5 \mathrm{~g} \cdot \mathrm{m}^{-2} . \mathrm{s}^{-1}$ if the dry air is further cooled to $40^{\circ} \mathrm{C}$ at inlet.

We also used the flow model to determine the optimum conditions for maximum WVT flux for different operating pressures and temperatures. We found that the WVT flux is highest if the wet and dry inlet gas temperatures are selected such that, throughout the humidifier, the wet stream is maintained at close to $100 \% \mathrm{RH}$ at local temperature, and the dry stream is prevented from approaching $100 \%$ saturation anywhere in the humidifier. The overall water transport flux is 
mainly determined by the gradient in RH (rather than the difference in partial pressure of water vapor) of the wet and dry streams but it is also affected by vapor diffusion in the gas layer and the microporous layer.

\section{Nomenclature}

$a$ activity of water vapor

$c_{p} \quad$ specific heat

E equivalent weight

$J \quad$ water vapor flux

K mass transfer coefficient

M molecular weight

$q \quad$ heat flux

$T \quad$ temperature

$U$ heat transfer coefficient

$v \quad$ gas velocity in wet channel

$x \quad$ thickness direction

$z \quad$ dry gas flow direction

$\delta \quad$ thickness

\section{Subscripts and Superscripts}

$\rho \quad$ density

$d \quad$ dry

eff effective

$v \quad$ vapor
C molar concentration

D water vapor diffusivity

i enthalpy

$k \quad$ thermal conductivity

$L \quad$ half height of channel

$P \quad$ pressure

$R$ mass transfer resistance

$t \quad$ time

$\mathrm{u} \quad$ gas velocity in $\mathrm{x}$ direction

$w \quad$ gas velocity in dry channel

$y \quad$ wet gas flow direction

$\beta \quad$ interfacial kinetics

$\lambda \quad$ water uptake in ionomer

$\tau \quad$ shear stress

$e \quad$ ePTFE

$m \quad$ ionomer

w wet 


\section{Acknowledgements}

This work was supported by the Fuel Cell Technologies Office of the U.S. Department of Energy's (DOE) Office of Energy Efficiency and Renewable Energy. Dr. Nancy Garland and Mr. Jason Marcinkoski were the DOE Technology Development Manager for this work. Argonne is a

DOE, Office of Science Laboratory operated under Contract No. DE-AC02-06CH11357 by UChicago, Argonne, LLC.

\section{References}

1. R. K. Ahluwalia, X. Wang, Direct Hydrogen Fuel Cell Systems for Hybrid Vehicles, J. Power Sources 152 (2005) 233-244.

2. R. K. Ahluwalia, X. Wang, Fuel Cell Systems for Transportation: Status and Trends, J. Power Sources 177 (2008) 167-176.

3. W. Liu, K. Ruth, G. Rusch, Membrane Durability in PEM Fuel Cells, J. New. Mat. Electrochem. Systems 4 (2001) 227-231.

4. C. Houchins, G. J. Kleen, J. S. Spendelow, J. Kopasz, D. Peterson, N. L. Garland, D. L. Ho, J. Marcinkoski, K. E. Martin, R. Tyler, D. C. Papageorgopoulos, U.S. DOE Progress towards Developing Low-Cost, High Performance, Durable Polymer Electrolyte Membranes for Fuel Cell Applications, Membranes 2 (2012) 855-878.

5. R. K. Ahluwalia, X. Wang, Performance of Advanced Automotive Fuel Cell Systems with Heat Rejection Constraints, FY 2014 Annual Progress Report for the DOE Hydrogen and Fuel Cells Program, DOE/GO-102014-4504 V.I.1, Nov. 2014.

6. K. E. Martin, J. P. Kopasz, The U.S. DOE's High Temperature Membrane Effort, Fuel Cells 9 (2009) 356-362. 
7. A. Chandan, M. Hattenberger, A. El-kharouf, S. Du, A. Dhir, V. Self, B. G. Pollet, A. Ingram, W. Bujalski, High Temperature (HT) Polymer Electrolyte Membrane Fuel Cells (PEMFC) A Review, J. Power Sources 231 (2013) 264-278.

8. R. D. Breault, Method and Apparatus for Increasing the Operational Efficiency of a Fuel Cell Power Plant, U.S. Patent 6,682,835, Jan. 27, 2004.

9. G. J. Koncar, L. G. Marianowski, Proton Exchange Membrane Fuel Cell Separator Plate, U. S. Patent 5,942,347, Aug. 24, 1999.

10. P. D. Hood, P. L. Adcock, Fuel Cell Direct Water Injection, U. S. Patent 8,614,030, Dec. 24, 2013.

11. R. A. Dubose, Fuel Cell Gas Management System, U. S. Patent 6,013,385, Jan. 11, 2000.

12. T. P. Smith, D. A. Leighty, Method and Apparatus for Water Vapor Transfer, U. S. Patent Application Publication, US 2002/0155328, Oct. 24, 2002.

13. Z. Mirza, Development of a Thermal and Water Management System for PEM Fuel Cell, DE-FC36-03GO13109 Final Report (11-77418), Oct.5, 2012.

14. K. Yamakawa, W. B. Johnson, M. Murthy, T. Berta, Composite Membrane and Moisture Adjustment Module Using Same, United States Patent Application Publication, US 20090324929, Dec. 31, 2009.

15. W. B. Johnson, Materials and Modules for Low Cost, High Performance Fuel Cell Humidifiers, DE-EE0000465 Final Report, Energy Efficiency and Renewable Energy, U.S. Department of Energy, 2014.

16. Textiles - Measurement of Water Vapour Permeability of Textiles for the Purpose of Quality Control, ISO 15496, 2004. 
17. N. S. Khattra, M. H. Santare, A. M. Karlsson, T. Schmiedel, F. C. Busby, Effect of Water Transport on Swelling and Stresses in PFSA Membranes, Fuel Cells 15 (2015) 178-188.

18. Z. Ma, R. Jiang, M. E. Myers, E. L. Thompson, C. S. Gittleman, NMR Studies of Proton Transport in Fuel Cell Membranes at Sub-Freezing Conditions, J. Mater. Chem. 21 (2011) 9302-9311.

19. D. E. Kadylak, Effectiveness Method for Heat and Mass Transfer in Membrane Humidifiers, M.S. Thesis, Dept. of Mech. Eng., The University of British Columbia, 2009.

\section{Figure Captions}

Figure 1 Ionomer sandwiched between microporous layers to form an optimized humidification membrane

Figure 2 Water transport measurements

Figure 3 Permeance of M311.05 membrane from static and dynamic tests

Figure 4 Comparative performance of humidification membranes

Figure 5 Humidifier module and model framework

Figure 6 Mass transfer resistances (a) derived from measured water flux in static (b) and dynamic (c) tests

Figure 7 Modeled RH profiles in cross-flow dry and wet streams

Figure 8 Humidifier model validation - water flux

Figure 9 Humidifier model validation - effectiveness

Figure 10 Model calibration

Figure 11 Assessment of humidifier performance at reference conditions

Figure 12 Humidifier performance as function of dry air inlet temperature and approach dewpoint temperature

Figure 13 Humidifier performance at optimum operating conditions 


\section{Table Captions}

Table 1 Module Performance Test Series

Table 2 Model Constants Derived from Dynamic and Pseudo-Static Permeance Data 
Table 1 Module Performance Test Series

$\begin{array}{ccccccl}\text { Series } & \text { Flow Rate } & \mathrm{P} & \text { Dry Inlet } \mathrm{T} & \text { Wet Inlet } \mathrm{T} & \mathrm{RH} & \text { Comments } \\ & \mathrm{g} \cdot \mathrm{s}^{-1} & \mathrm{bar} & { }^{\circ} \mathrm{C} & { }^{\circ} \mathrm{C} & \% & \\ \mathrm{~A} & 27 & 1.25,1.6,2.2 & 63-64 & 59-64 & 62-89 & \text { Direct water injection for } \mathrm{RH} \text { control } \\ \mathrm{B} & 45 & 1.35,1.5,1.9 & 65-66 & 56-65 & 43-81 & \text { Instrument limits maximum } \mathrm{RH} \\ \mathrm{C} & 55 & 1.5,1.7,2.0 & 66-68 & 52-63 & 49-87 & \\ \mathrm{D} & 72 & 1.4,1.7,1.9 & 65-68 & 47-59 & 44-86 & \\ \mathrm{M} & 7-76 & 1.2-2.3 & 30-74 & 33-70 & 59-95 & \mathrm{P}, \mathrm{T} \text { and } \mathrm{Q} \text { varied simultaneously }\end{array}$


Table 2 Model Constants Derived from Dynamic and Pseudo-Static Permeance Data

\begin{tabular}{ccc|ccc} 
Variable & Unit & Value & Variable & Unit & Value \\
$f^{e}$ & & 0.2 & $\mathrm{k}_{\mathrm{e}}$ & $\mathrm{W} . \mathrm{m}^{-1} \mathrm{~K}^{-1}$ & 0.15 \\
$\mathrm{k}_{\mathrm{m}}$ & $\mathrm{W} . \mathrm{m}^{-1} \mathrm{~K}^{-1}$ & 0.12 & $L_{d}$ & $\mathrm{~mm}$ & 0.6 \\
$L_{w}$ & $\mathrm{~mm}$ & 0.6 & $\mathrm{Nu}$ & & 8 \\
$R_{d}\left(23^{\circ} \mathrm{C}\right)$ & $\mathrm{s} . \mathrm{m}^{-1}$ & 6.5 & $R_{w}\left(23^{\circ} \mathrm{C}\right)$ & $\mathrm{s} . \mathrm{m}^{-1}$ & 6.5 \\
$R_{d}\left(80^{\circ} \mathrm{C}\right)$ & $\mathrm{s} . \mathrm{m}^{-1}$ & 7.5 & $R_{w}\left(80^{\circ} \mathrm{C}\right)$ & $\mathrm{s} . \mathrm{m}^{-1}$ & 7.5 \\
$R_{i}\left(23^{\circ} \mathrm{C}\right)$ & $\mathrm{s} . \mathrm{m}^{-1}$ & 1.0 & $R_{i}\left(80^{\circ} \mathrm{C}\right)$ & $\mathrm{s} . \mathrm{m}^{-1}$ & 6.6
\end{tabular}






Figure 1 Ionomer sandwiched between microporous layers to form an optimized humidification membrane 


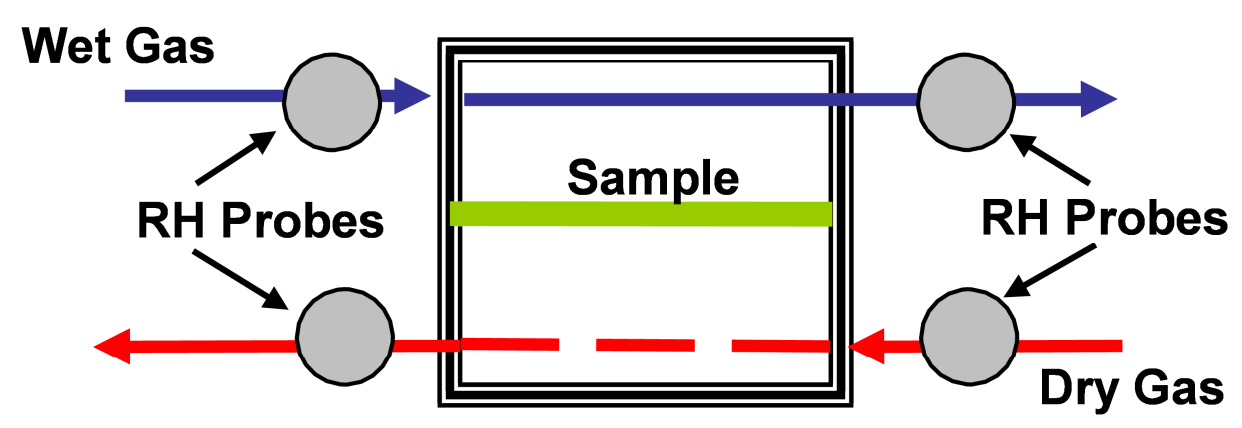

a) Schematic of dynamic test apparatus

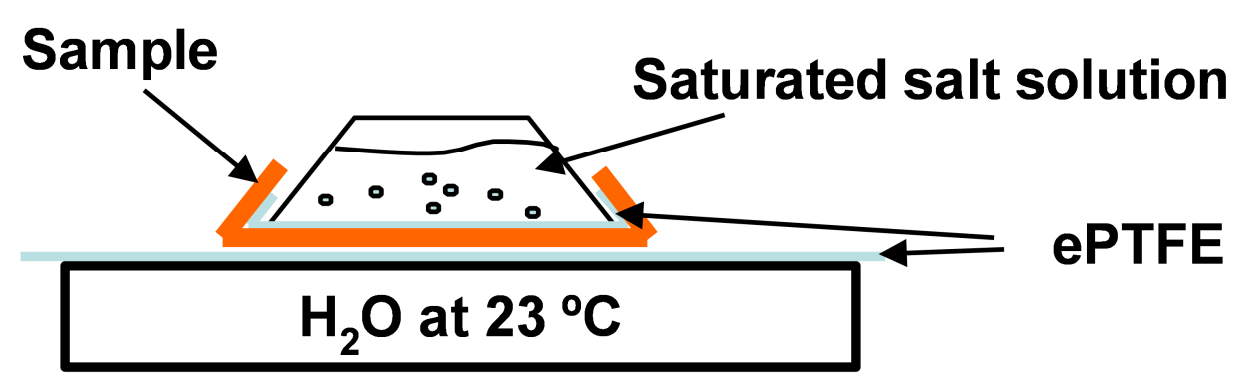

b) Pseudo-static test apparatus at $23^{\circ} \mathrm{C}$



c) Pseudo-static test apparatus at $80^{\circ} \mathrm{C}$

Figure 2 Water transport measurements 


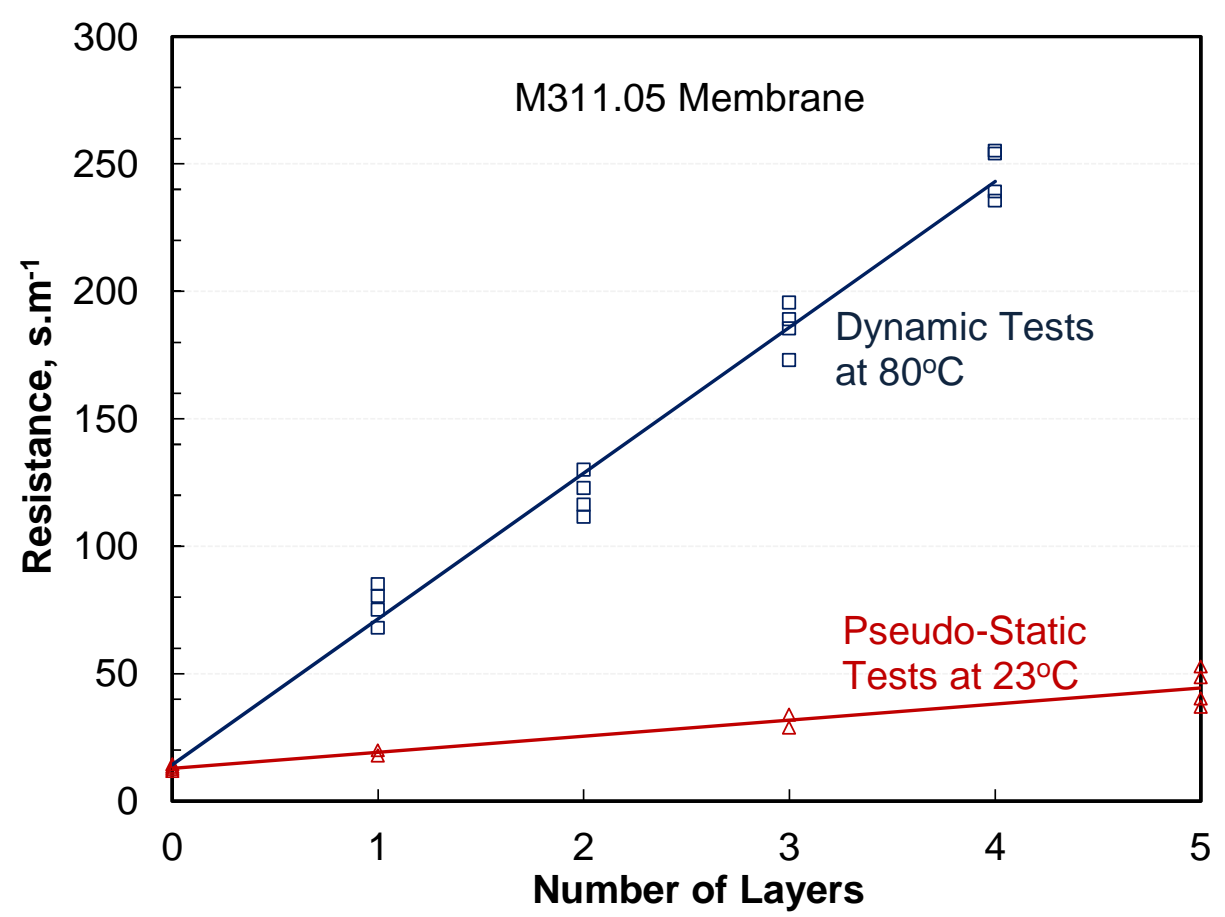

Figure 3 Permeance of M311.05 membrane from static and dynamic tests 


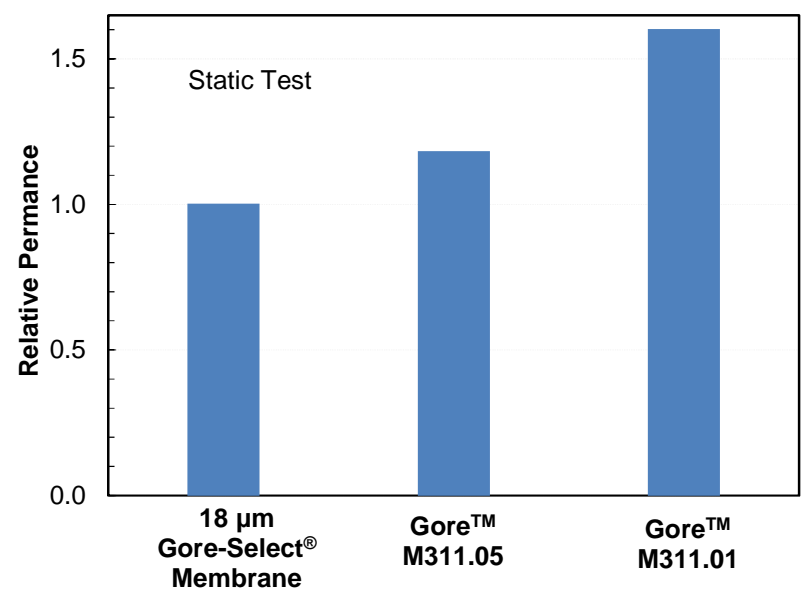

(a) Relative permeance in static tests at $23^{\circ} \mathrm{C}$





(b) Dynamic permeance test results at $80^{\circ} \mathrm{C}$

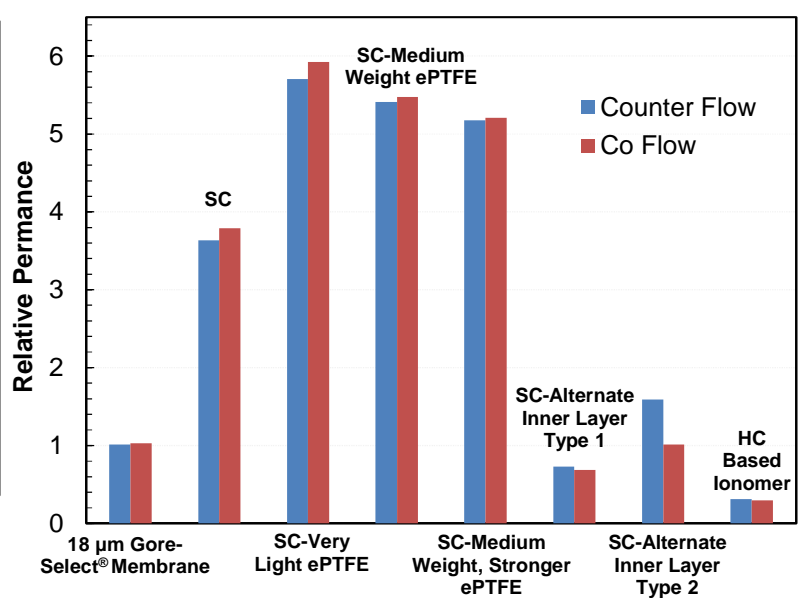

(c) Static vs. dynamic permeance at $80^{\circ} \mathrm{C}$ (d) Screening of different ionomers and ePTFE types

Figure 4 Comparative performance of humidification membranes 


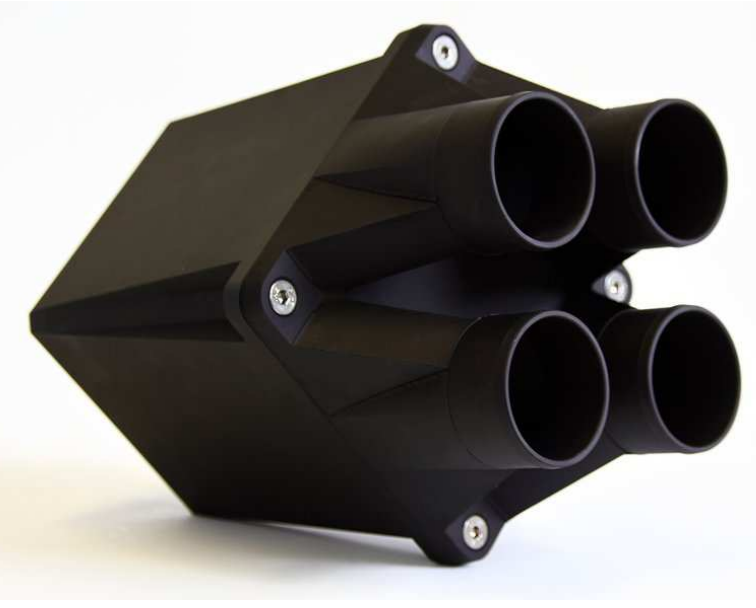

(a) Module housing

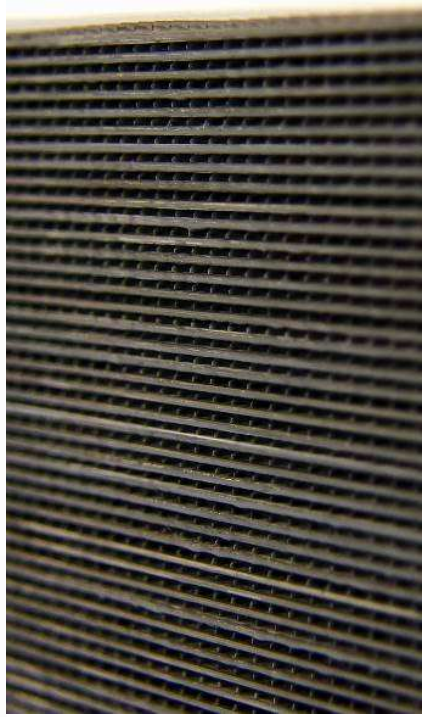

(b) Cross-flow flow fields

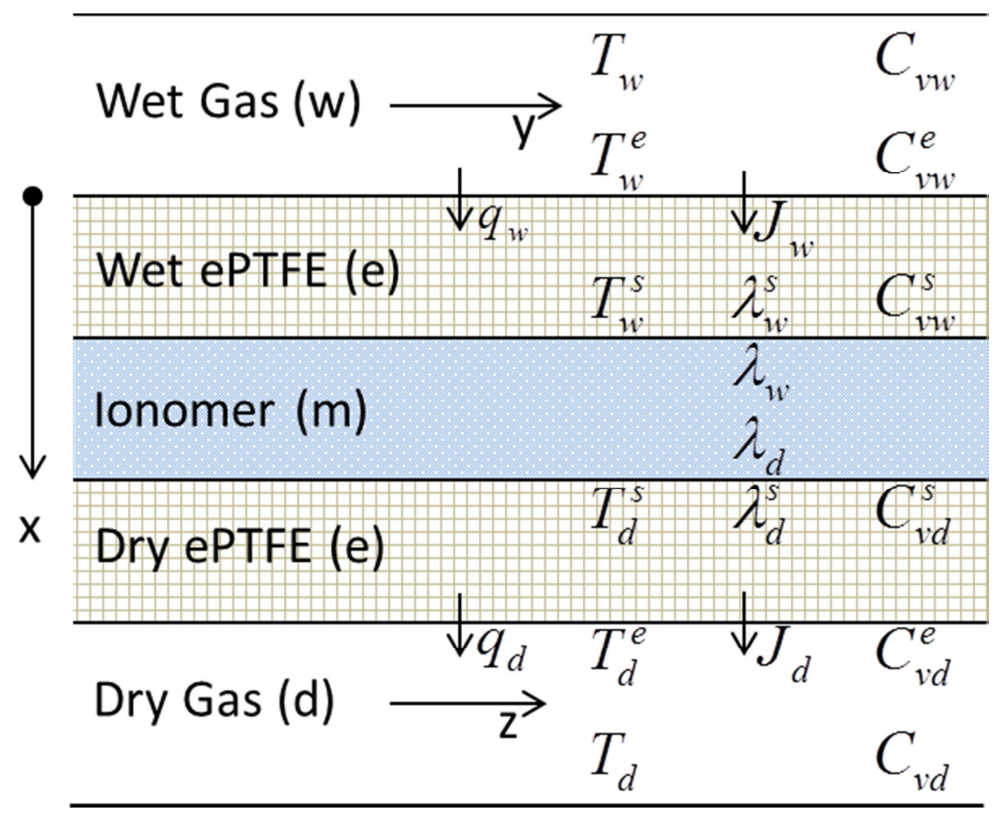

(b) Model reference framework

Figure 5 Humidifier module and model framework 

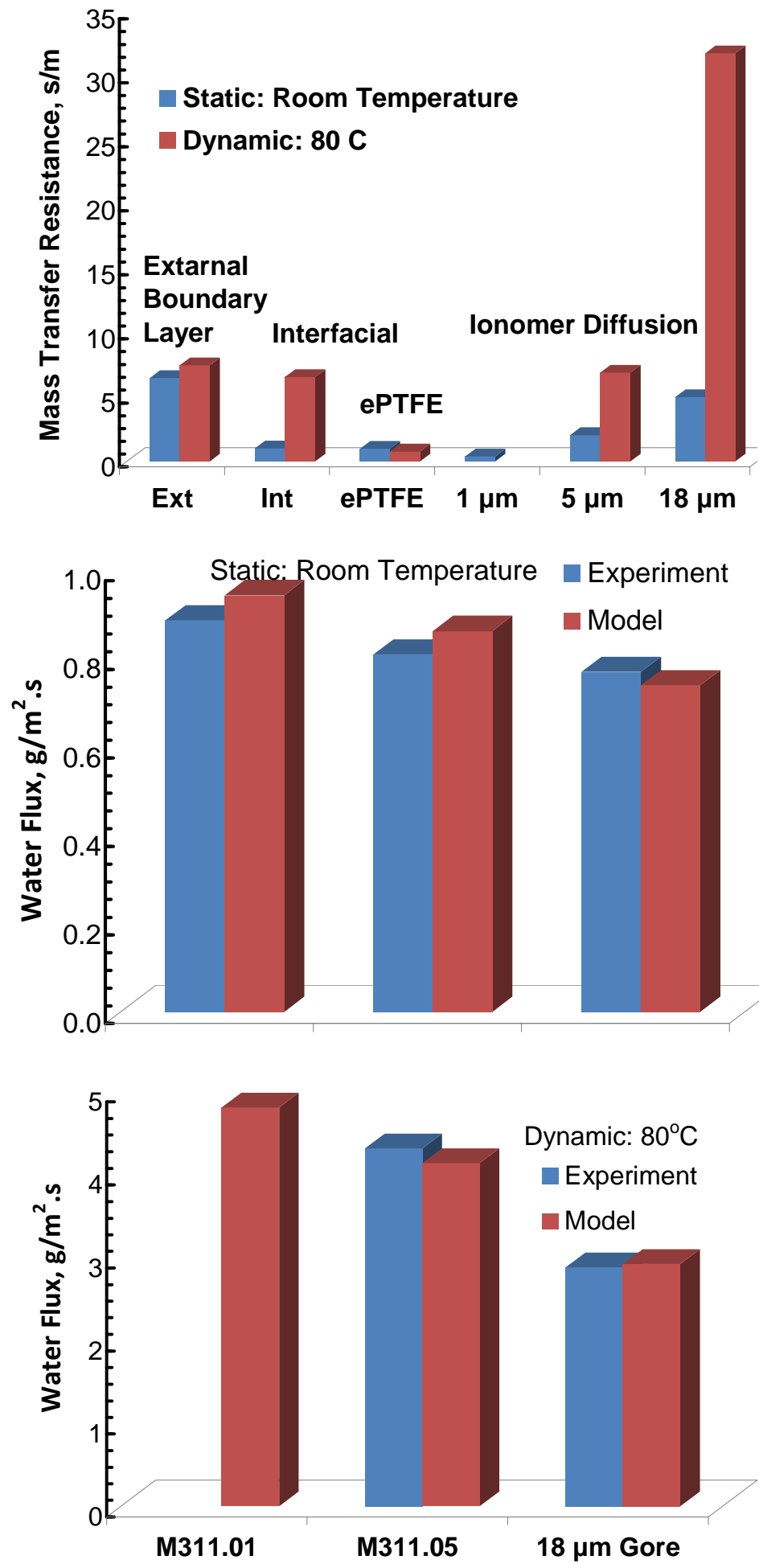

Figure 6 Mass transfer resistances derived from measured water flux in static and dynamic tests 


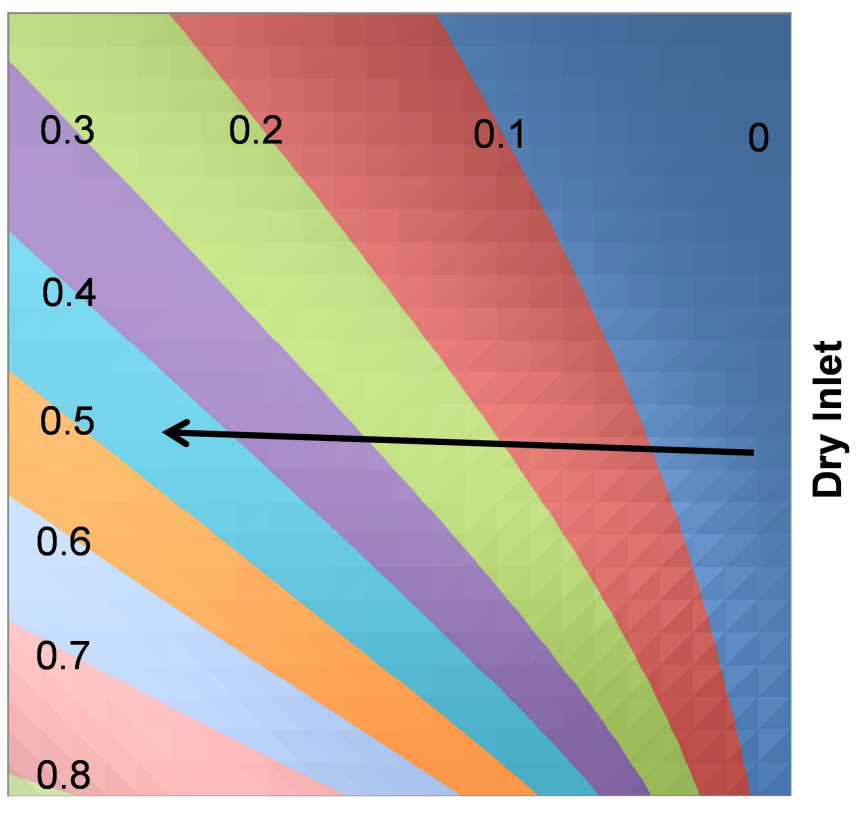

Wet Inlet



Figure 7 Modeled RH profiles in cross-flow dry and wet streams 

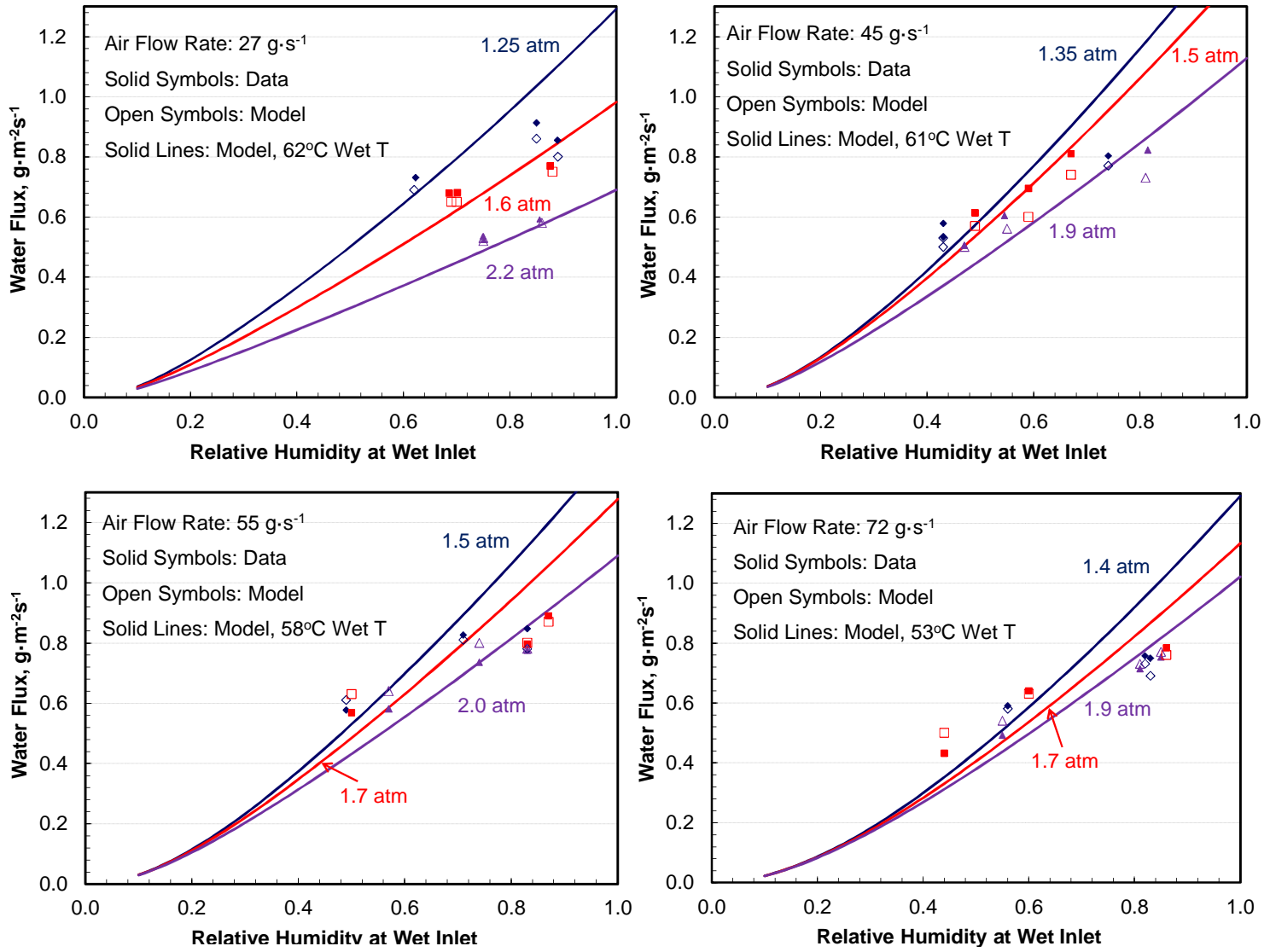

Figure 8 Humidifier model validation - water flux 



Figure 9 Humidifier model validation - effectiveness 

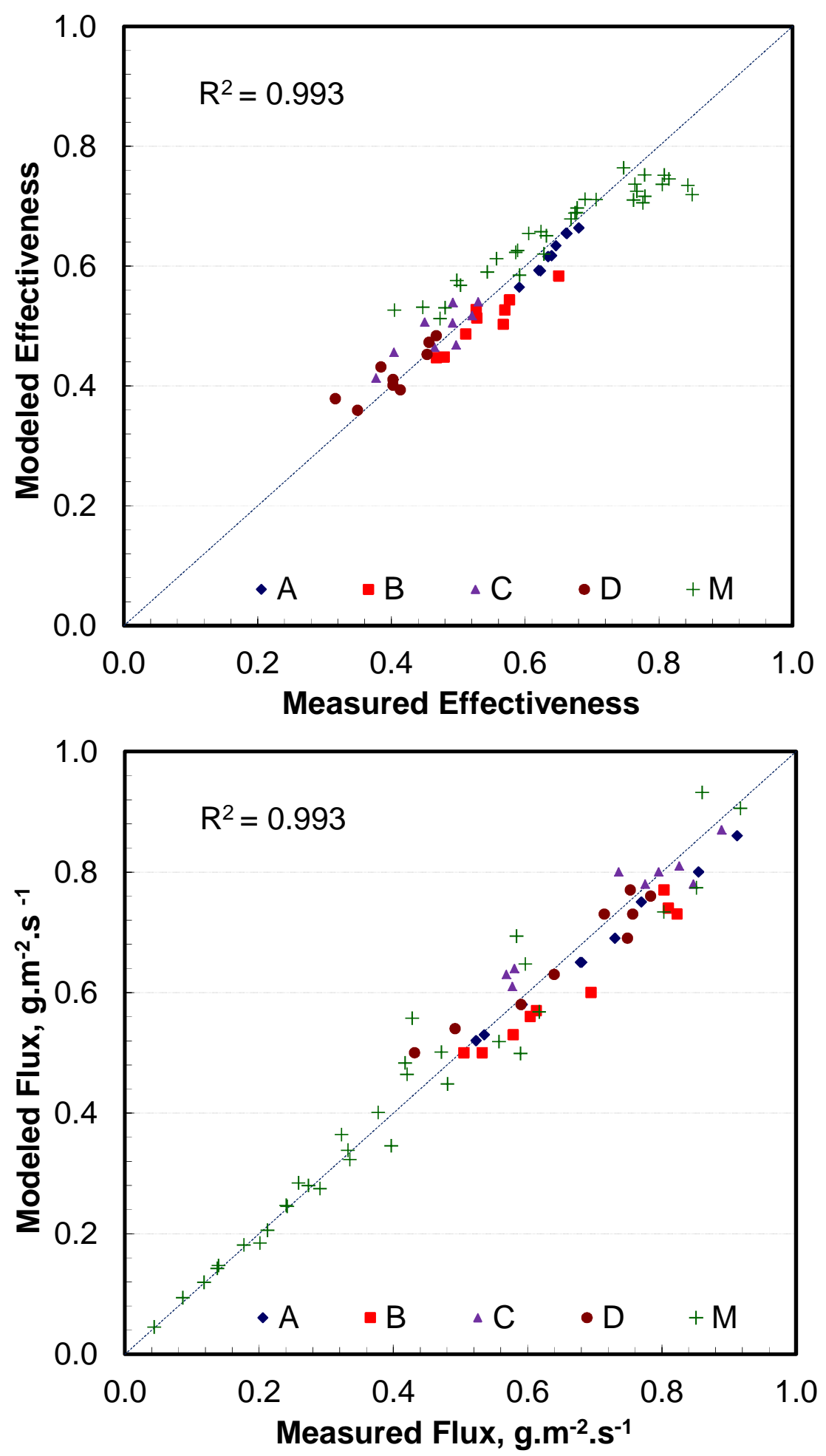

Figure 10 Model calibration 


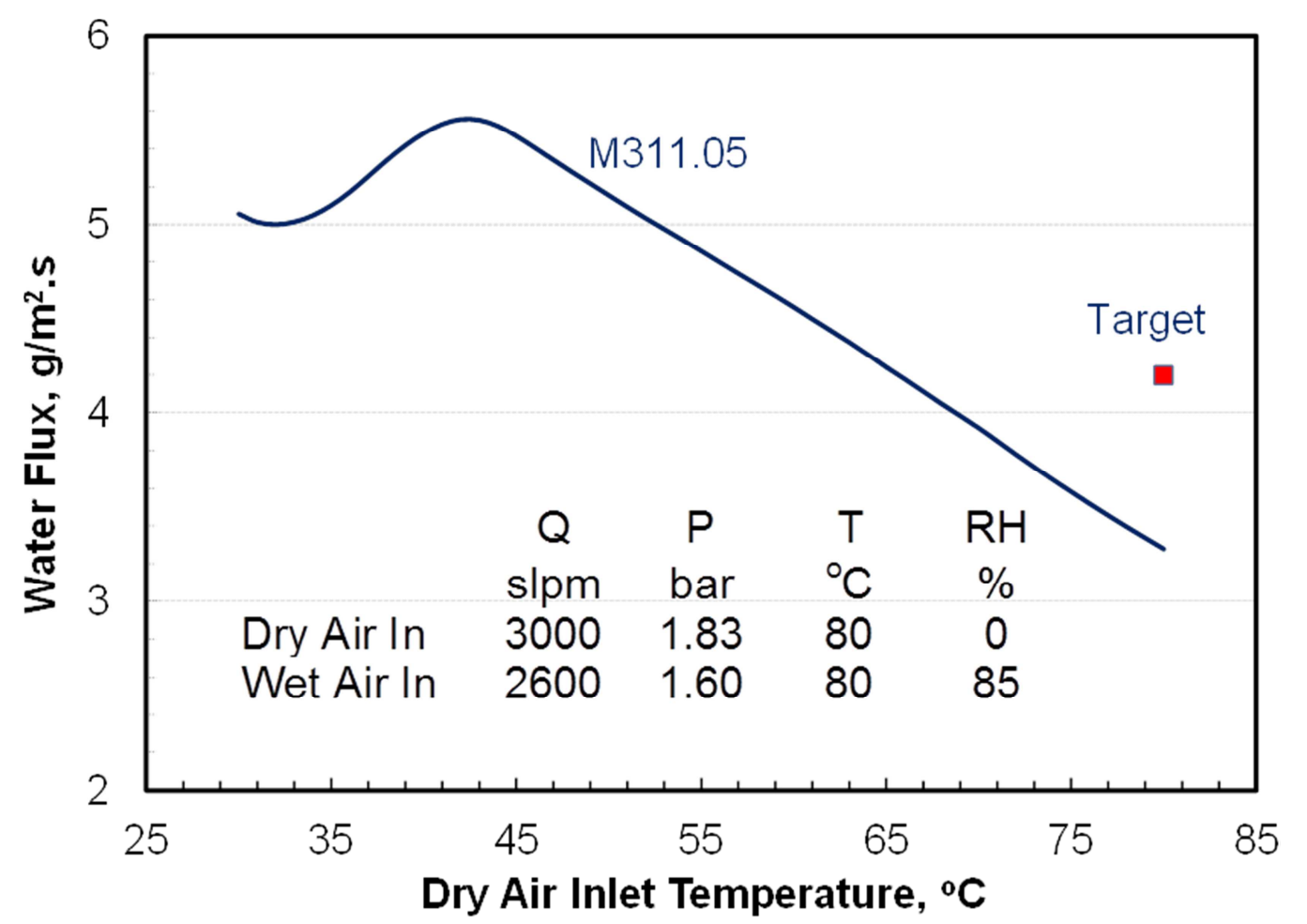

Figure 11 Assessment of humidifier performance at reference conditions 



Figure 12 Humidifier performance as function of dry air inlet temperature and approach dewpoint temperature 


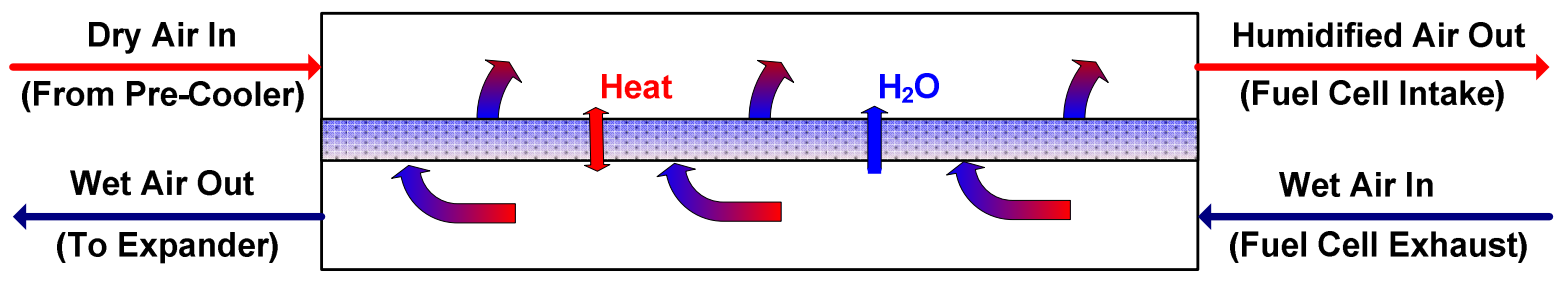
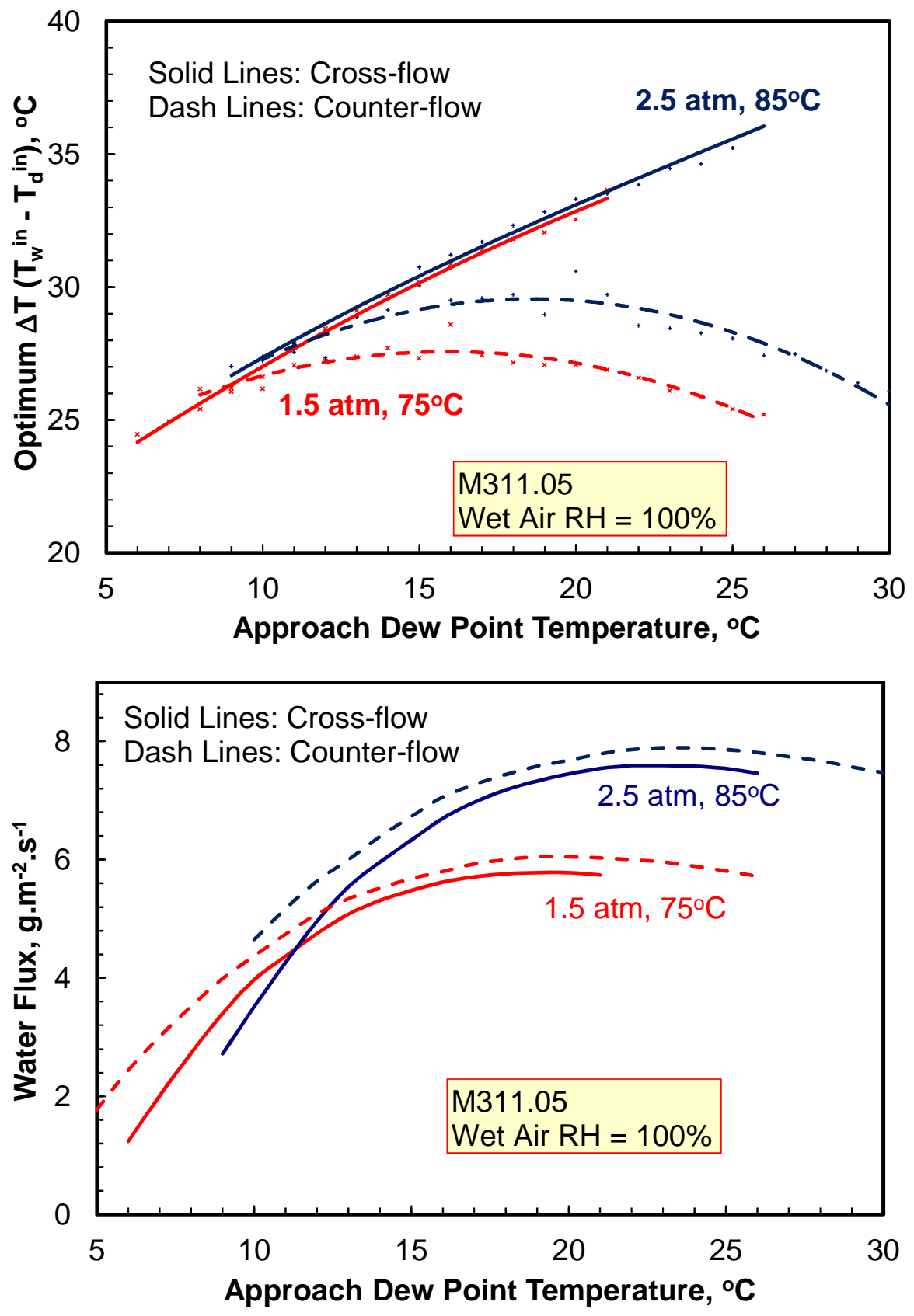

Figure 13 Humidifier performance at optimum operating conditions 


\section{Highlights}

- Fabricated composite membranes with PFSA ionomer and microporous ePTFE layers.

- Measured the permeance of composite membranes in dynamic and pseudo-static tests.

- Optimized the membranes for high permeance, adequate durability, and low cost.

- Built and tested full-scale cross-flow humidifier using the composite membranes.

- Developed a model to determine the operating conditions for high transport fluxes. 